\title{
Assessment of Awareness of Medical Students Toward Paralytic Ileus After Colon Surgery
}

\author{
Abrar Saad Alshareef, Anwar Mohammed Omer Basri, Bashaer Ibrahim Ahmed, Areen \\ Jibreel Khamaj
}

Ibn Sina National College-Jeddah-kingdom of Saudi Arabia

\begin{abstract}
Background: Protocols for bowel management have been used adequately among postoperative patients to maintain the normal GIT function and prevention of ileus among critically ill patients.

Objectives: Evaluating the knowledge, attitude and practice (KAP) of medical students about paralytic ileus after colon surgery at Kingdom of Saudi Arabia (KSA).

Methods: It is a randomized cross sectional study that was conducted during the period from March 2018 to June 2018, at Saudi Arabia among 320 medical students at the 5 thacademicyear.The study was based on a questionnaire sheet with an interview that included questions about knowledge, attitude and practice pattern of the students about paralytic ileus after surgery.

Results: The study included 320 medical students from different universities at the stage of fifth academic year. All of the included subjects had good knowledge about the definition of ileus, its symptoms and the initial treatment with intravenous fluids. Most of them have adequate knowledge about effect of epidural anesthesia on the duration of ileus $(82.5 \%)$, the complications of ileus $(67.5 \%)$, the paralysis of the bowel $(86.3 \%)$ and the diagnostic importance of CT $(87.8 \%)$. The attitude of most of the participants was good toward the importance of good nursing and efficient doctors to overcome the risks of postoperative ileus, the efficiency of bowel protocols and increasing the knowledge of the staff is adequate for prevention of ileus. The practice pattern was found to be adequate among the majority of participants as $81 \%$ would take care while using analgesics and sedatives and $90 \%$ would encourage movement of patient when possible. All of the subjects had adequate practice toward managing dietary nutrition, constipation and diarrhea.

Conclusion: The level of knowledge was adequate among most of the students which resulted in proper attitude and practicing pattern that encourage educating the health staff about ileus and how to be efficient in managing the bowel protocols.
\end{abstract}

Keywords: Awareness, paralytic ileus, colon surgery, medical students, KSA, 2018.

\section{INTRODUCTION}

Ileus is defined as a paralysis or closure of the bowel that delay and prevent the intestinal content passage whichmay result in accumulation of the content at the blocking site. It can be divided into two types either functional or mechanical ${ }^{(\mathbf{1})}$.

The signs of ileus include nausea, cramps, retention of stool and flatus as well as vomiting. After longstanding ileus, the symptoms are increased to major illness, constipation and long hospital stay ${ }^{(2)}$.

As for postoperative ileus, many protocols have been established to prevent it however it is one of the most common types after abdominal surgery. It could result in long hospital stay, more medications and costs ${ }^{(3)}$.

All surgeons, physicians, nurses and medical staff should have good knowledge, attitude and practice about the bowel protocols that could result in decreasing the number of cases after surgery and preventing its initiation. Also, the emergent management of bowel is a multimodality care plan which includes using analgesia, enhancing feeding, chewing, movement and ambulation, are the gold standards of bowel care ${ }^{(4)}$.
This study hypothesized that good knowledge among medical students would result in good attitude and practice which in turn would decrease the risk of postoperative ileus or even prevent it.

\section{AIM OF THE STUDY}

The present study aimed at evaluatingthe knowledge, attitude and practice (KAP) of medical students about paralytic ileus after colon surgery.

\section{METHODS}

\section{Study design:}

It is a randomized cross sectional study that was conducted in Saudi Arabia during the period from March 2018 to June 2018.

\section{Study population and sample size:}

The study included 320 medical students at $5^{\text {th }}$ year who were chosen from different 3 universities using multiple stratified random sampling techniques. The students were interviewed at the balls of their college and they gave a written consent for their approval to participate in the present study. 


\section{Study tools:}

The study was based on a questionnaire sheet with an interview. The questionnaire was conducted among 20 students in a pilot study to assess its efficiency and validity. The questionnaire was reviewed by 3 experts then translated into Arabic. The questionnaire included questions about knowledge, attitude and practice pattern of the students about paralytic ileus after surgery.

\section{Statistical analysis:}

The statistical analysis was done using the Statistical Package for Social Sciences version 20 (SPSS Inc., Chicago, IL, USA) using simple descriptive and analytical methods showed as frequency and percentage.

\section{RESULTS}

\section{Characteristics of the participants:}

The study included 320 medical students from different universities at the fifth year where they answered the questionnaire about their KAP toward paralytic ileus after colon surgery.

\section{Level of awarenessamong included students:}

Table 1 is indicates the level of knowledge among the respondents. All of the included subjects had good knowledge about the definition of ileus and its symptoms. Also, most of them have adequate knowledge about effect of epidural anesthesia on the duration of ileus (82.5\%), the complications of ileus $(67.5 \%)$ and the paralysis of the bowel $(86.3 \%)$. On the other hand, the knowledge was in adequate among $65.9 \%$ about the usage of procalcitionin as diagnostic marker for bowel ischemia. The majority of students were aware about the diagnostic tool used for ileus as CT (87.8\%) and all of them had good knowledge about the importance of intravenous fluids as the initial treatment at emergency room.

Table (1): Awareness of the included participants about ileus (320).

\begin{tabular}{|c|c|c|}
\hline & Correct & Incorrect \\
\hline $\begin{array}{l}\text { 1. Ileus is temporary delay in gastrointestinal (GI) } \\
\text { motility after surgery? }\end{array}$ & $320(100 \%)$ & $0(0 \%)$ \\
\hline $\begin{array}{ll}2 . & \text { The symptoms of ileus include: } \\
- & \text { Nausea } \\
- & \text { Vomiting } \\
- & \text { abdominal distention } \\
- & \text { abdominal tenderness } \\
- & \text { delayed passage of flatus and stool }\end{array}$ & $\begin{array}{l}320(100 \%) \\
320(100 \%) \\
320(100 \%) \\
320(100 \%) \\
320(100 \%)\end{array}$ & $0(0 \%)$ \\
\hline 3. Epidural anesthesia can shorten duration of ileus & $264(82.5 \%)$ & $56(17.5 \%)$ \\
\hline $\begin{array}{l}\text { 4. Ileus lead to fluid shifts, transmigration peritonitis, } \\
\text { and hypovolemia }\end{array}$ & $216(67.5 \%)$ & $\begin{array}{c}104 \\
(32.5 \%)\end{array}$ \\
\hline $\begin{array}{l}\text { 5. Bowel damage can cause paralysis without any } \\
\text { peristaltic activity }\end{array}$ & $276(86.3 \%)$ & $44(13.7 \%)$ \\
\hline $\begin{array}{l}\text { 6. Procalcitonin concentration is a potentially useful } \\
\text { marker for bowel ischemia }\end{array}$ & $109(34.1 \%)$ & $\begin{array}{c}211 \\
(65.9 \%)\end{array}$ \\
\hline $\begin{array}{l}\text { 7. Abdominal computed tomography (CT) is the gold } \\
\text { standard diagnostic tool for postoperative ileus }\end{array}$ & $281(87.8 \%)$ & $39(12.2 \%)$ \\
\hline $\begin{array}{l}\text { 8. Intravenous fluid administration is the initial } \\
\text { treatment at emergency room }\end{array}$ & $320(100 \%)$ & $0(0 \%)$ \\
\hline
\end{tabular}

\section{The awareness score among participants:}

The knowledge was adequate among $77.2 \%$ of students showing high awareness level (Table. 2).

Table (2): Respondents' knowledge of epilepsy among children.

\begin{tabular}{|c|c|c|}
\hline Knowledge level & Frequency & Percent (\%) \\
\hline Good & 247 & 77.2 \\
\hline Poor & 73 & 22.8 \\
\hline Total & 320 & 100.0 \\
\hline
\end{tabular}

\section{The attitude of included subjects:}

The attitude of most of the participants was good $(93.1 \%)$ toward the importance of good nursing and efficient doctors to overcome the risks of postoperative ileus. All of them has positive attitude toward the efficiency of bowel protocols and about 65.9 as well as 94.1 thought that different physicians could be a risk for improper management and increasing the knowledge of the staff is adequate for prevention of ileus.

Table (3): Attitude of included students toward ileus $(n=320)$.

\begin{tabular}{|l|c|c|}
\hline & No. & $\begin{array}{c}\text { Percentage } \\
(\%)\end{array}$ \\
\hline $\begin{array}{l}\text { Poor nursing and laziness of } \\
\text { doctors are possible risk factors for } \\
\text { postoperative ileus }\end{array}$ & & \\
\hline Agree & 298 & 93.1 \\
\hline Disagree & 22 & 6.9 \\
\hline $\begin{array}{l}\text { Bowel protocols management are } \\
\text { adequate for avoiding ileus }\end{array}$ & & \\
\hline Yes & 320 & 100 \\
\hline No & 0 & 0 \\
\hline $\begin{array}{l}\text { Different physicians at shifts could } \\
\text { result in an adequate care of bowels } \\
\text { after surgery }\end{array}$ & & \\
\hline Yes & 211 & 65.9 \\
\hline No & 109 & 34.1 \\
\hline $\begin{array}{l}\text { Increasing the knowledge of nurses } \\
\text { and staff supervision is good for } \\
\text { prevention of postoperative ileus }\end{array}$ & 301 & 94.1 \\
\hline Agree & 19 & 5.9 \\
\hline Disagree & & \\
\hline
\end{tabular}

\section{Attitude score among included students:}

The attitude of the included participants was presented in table 4 (Table. 4).

Table (4): Attitude score among respondents.

\begin{tabular}{|c|c|c|}
\hline KAP level & Frequency & Percent (\%) \\
\hline Good & 276 & 86.2 \\
\hline Poor & 44 & 13.8 \\
\hline Total & 320 & 100.0 \\
\hline
\end{tabular}




\section{Practice pattern of included subjects:}

The practice pattern was found to be adequate among the majority of participants as 81 $\%$ would take care while using analgesics and sedatives. All of the subjects had adequate practice toward managing dietary nutrition, constipation and diarrhea. Also, about 90\% would encourage the movement of patients when possible (Table. 5).

Table (5): The Practice pattern of included students $(\mathrm{n}=320)$.

\begin{tabular}{|l|c|c|}
\hline & No. & $\begin{array}{c}\text { Percentage } \\
(\%)\end{array}$ \\
\hline $\begin{array}{l}\text { Take care while choosing analgesics } \\
\text { and sedatives }\end{array}$ & & \\
\hline Yes & 259 & 81 \\
\hline No & 61 & 19 \\
\hline $\begin{array}{l}\text { Adequate dietary nutrition must be } \\
\text { implanted when possible }\end{array}$ & & \\
\hline Yes & 320 & 100 \\
\hline No & 0 & 0 \\
\hline $\begin{array}{l}\text { Management of constipation and } \\
\text { diarrhea is essential for } \\
\text { management }\end{array}$ & & \\
\hline Yes & 320 & 100 \\
\hline No & 0 & 0 \\
\hline $\begin{array}{l}\text { Encourage the movement of the } \\
\text { patients when possible }\end{array}$ & & \\
\hline Yes & 288 & 90 \\
\hline No & 32 & 10 \\
\hline
\end{tabular}

\section{Practice score among respondents:}

The practice pattern was sufficient among $91.6 \%$ of students.

Table (6): The practice pattern among participants.

\begin{tabular}{|l|c|c|}
\hline \multicolumn{1}{|c|}{ Practice level } & Frequency & Percent (\%) \\
\hline Good & 293 & 91.6 \\
\hline Poor & 27 & 8.4 \\
\hline Total & 320 & 100.0 \\
\hline
\end{tabular}

\section{DISCUSSION}

Protocols for bowel management have been used adequately among postoperative patients to maintain the normal GIT function and prevention of ileus among critically ill patients ${ }^{(3)}$. After reviewing the available studies on medical search engines, there were no available studies in the same pattern with this present study thus this is the first study conducted among medical students to study their KAP toward paralytic ileus after colon surgery and this is one of the interesting factors in this study.

This study also has some limitations including the questionnaire which was formulated based on some available studies about the definition, pathogenesis and management protocols of postoperative ileus. Also, all the included students were from the same academic year thus their knowledge can't be generalized on all of the medical students in different academic years.

This study showed a higher level of KAP among students which could be attributed to their proper knowledge during the fifth academic year. Many studies have shown the same definition, pathogenesis, diagnosis and treatment options as the present study.

In accordance, the ileus was defined as a impermanent delay in the motility of the gastrointestinal (GI) after surgery resulting in postoperative ileus ${ }^{(5)}$. The signs of paralytic ileus include nausea, tenderness and distention of the abdomen and associated with high postoperative costs for recovery as well as increasing the hospital stay ${ }^{(6)}$.

Consistently, the use of epidural anesthesia can lessen the duration of postoperative ileus and control pain ${ }^{(4)}$. Also, procalcitonin was a useful diagnostic marker for abdominal ischemia in many studies ${ }^{(7)}$.

Abdominal computed tomography (CT) is the gold standard diagnostic technique for ileus with high specificity and sensitivity with using intravenous and oral contrast ${ }^{(8)}$. The initial treatment was found to be administrating intravenous fluid to correct the electrolyte imbalance and replace the lost body fluids ${ }^{(9)}$.

\section{CONCLUSION}

The level of knowledge was adequate among most of the students which resulted in proper attitude and practicing pattern that encourage educating the health staff about ileus and how to be efficient in managing the bowel protocols.

\section{REFERENCES}

1- Vilz T, Stoffels B, Strassburg C et al. (2017): Ileus in Adults: Pathogenesis, Investigation and Treatment. Deutsches Ärzteblatt International, 114:508-518.

2- Behm B and Stollman N (2003): Postoperative ileus: etiologies and interventions. Clinical gastroenterology and hepatology : the official clinical practice journal of the American Gastroenterological Association, 1:71-80. 
3- Carroll J and Alavi K (2009): Pathogenesis and Management of Postoperative Ileus. Clinics in Colon and Rectal Surgery, 22:47-50.

4- Person $B$ and Wexner SD (2006): The management of postoperative ileus. Curr Probl Surg., 43:6-65.

5- Artinyan A, Nunoo-Mensah JW, Balasubramaniam S et al. (2008): Prolonged postoperative ileus-definition, risk factors, and predictors after surgery. World journal of surgery, 32:1495-1500.

6- Holte $K$ and Kehlet $H$ (2002): Postoperative ileus: progress towards effective management. Drugs, 62:2603-2615.

7- Cosse C, Regimbeau JM, Fuks D et al. (2013): Serum procalcitonin for predicting the failure of conservative management and the need for bowel resection in patients with small bowel obstruction. Journal of the American College of Surgeons, 216:997-1004.
8- Branco BC, Barmparas G, Schnuriger B et al. (2010): Systematic review and metaanalysis of the diagnostic and therapeutic role of water-soluble contrast agent in adhesive small bowel obstruction. The British journal of surgery, 97:470-478.

9- Oyasiji T, Angelo S, Kyriakides TC et al. (2010): Small bowel obstruction: outcome and cost implications of admitting service. The American surgeon, 76:687-691. 